https://www.journal-imab-bg.org

Original article

\title{
ASSESSMENT OF RISK FACTORS OF OBSTET- RIC STATUS ASSOCIATED WITH PREMATURE BIRTHS IN WOMEN IN CHILDBIRTH
}

\author{
Irena Hristova ${ }^{1}$, Slavcho Tomov ${ }^{1}$, Nadezhda Hinkova ${ }^{1}$, Yordan Popov ${ }^{2}$, Joana \\ Simeonova ${ }^{3}$ \\ 1) Department of Midwifery, Faculty of Health Care, Medical University - \\ Pleven, Bulgaria \\ 2) Department of Obstetrics and Gynecology, Faculty of Medicine, Medical Uni- \\ versity - Pleven, Bulgaria \\ 3) Department of Social Medicine, Faculty of Public Health, Medical Univer- \\ sity - Sofia, Bulgaria.
}

\section{SUMMARY}

Purpose: To identify and assess the prevalence of the risk factors of obstetric status associated with premature births - total and according to maternal age at pregnancy.

Material and Methods: A case-control study was carried out in 2017 at the University Hospital - Pleven, including 1212 women in childbirth and 1212 live-born babies after single pregnancies. The women were divided into three age groups: under 19, 20-35 and over 35 years. The liveborn infants were divided into two groups. The cases included 120 preterm and low-birth-weight newborns (PLBWN). The controls included 955 full-term newborns with normal birth weight (FTNNBW). We did not include 37 full-term newborns with low birth weight (FTNLBW) and 100 preterm newborns with normal birth weight (PNNBW) in the study to control confounding effects. The role of 8 risk factors (RFs) on premature births was investigated.

Results: The prevalence of most RFs was higher in women under 18 and over 35 years of age compared with aged 20-35 years. Maternal pelvic size abnormalities $(\mathrm{OR}=3.31)$, breech presentation $(\mathrm{OR}=7.35)$, placental abnormalities $(\mathrm{OR}=4.23)$, caesarean birth $(\mathrm{OR}=2.28)$ increased the risk of preterm births and low birth weight.

Conclusions: There are many RFs associated with preterm births and low birth weight. These RFs need to be identified during pregnancy to reduce the prevalence of PLBWN and the health, economic and social consequences for children and their families, and for the health system and society.

Keywords: risk factors, obstetric status, women in childbirth, age groups, premature births

\section{INTRODUCTION}

The multifactor aetiology of pregnancy and premature birth in different age groups of mothers are still not well understood in Bulgaria. During the last 20 years, no complex assessment has been made of protective and risk factors for premature birth and low birth weight.

Prematurity has a greater impact on the physical and neuropsychological development of the children throughout their lives [1]. The risk of neurological diseases, problems with vision and learning deficits increases [2]. A number of poor health outcomes in preterm newborns occur later in life and increase the risk of developing chronic non-infectious diseases at an older age [3-7]. Prematurity has been one of the leading global burden of disease [812 ] and has negative effects on families, society and health systems [13].

Currently, the efforts of obstetricians, neonatologists and pediatricians are mostly oriented towards new health technologies to improve survival rates of preterm infants.

It is a challenge for both researchers and physicians to identify individuals or groups with high risk for pregnancy and delivery complications [14-16]. The preventive interventions to reduce preterm births and low-birth weight [17-19] should be effective and focused on reducing morbidity and health problems occurring in later life among premature infants.

The aim of the study was to identify and assess the prevalence of RFs of the obstetric status associated with premature births - total and according to maternal age at pregnancy.

\section{MATERIAL AND METHODS}

A case-control study was carried out in 2017 at the University Hospital - Pleven. There were 1248 births registered in 2017. The study included 1212 women in childbirth and 1212 live-born babies after single pregnancies. Respondents were chosen according to the following criteria: they should be registered at university hospital in Pleven in 2017 and data collected for the purpose of the study should be available.

The women were divided into three age groups: under $19(n=193), 20-35(n=862)$ and over 35 years $(n=157)$. The live-born infants were divided into two groups: cases and controls. The cases included 120 preterm low-birth- 
weight babies born before 37 gestational weeks (GW) and weighing less than 2500 grams $(\mathrm{g})$. The controls included 955 full-term newborns with normal birth weight (FTNNBW). We did not include in study 37 full-term newborns with low birth weight (FTNLBW) and 100 preterm newborns with normal birth weight (PNNBW) to control confounding effects.

The role of 8 risk factors (RFs) on premature births was investigated.

Data were collected from the pregnancy history about: last menstrual period (LMP), estimated date of confinement (EDC) and date of birth to estimate gestational age. The gestational age was measured in GW and calculated from the first date of the LMP. Birth weight of babies was measured immediately after delivery by weighing scale with $1 \mathrm{~g}$ accuracy.

Many RFs were studied: age of mothers, type of birth, amniotic fluid deficiency and congenital abnormalities, maternal pelvic size abnormalities, placental abnormalities, abnormalities of fetal membranes, umbilical cord abnormalities, and fetal presentation.

Data were processed by Statgraphics, SPSS v.24.0 and Excel for Windows. Mean and standard deviation $(\mathrm{Mean} \pm \mathrm{SD})$, as well as median and range (Min $\div$ Max) were used to describe the continuous variables. The categorical variables were described by number of cases and percentage. ANOVA and Pearson Chi-square were used. We assume the differences between groups are significant if the pvalue is less than or equal to 0.05 . Odds ratios (OR) for preterm birth and low-birth weight RFs were calculated.

\section{RESULTS}

Table 1 shows the distribution of the women in childbirth by sociodemographic characteristics.

Table 1. Distribution of mothers by sociodemographic characteristics (Number, \%)

\begin{tabular}{|l|l|l|l|l|l|}
\hline Variable & Number & $\mathbf{\%}$ & Variable & Number & $\mathbf{\%}$ \\
\hline Age & & & Place of residence & & \\
Mean age & $26.6 \pm 6.5$ & & Urban & 678 & 56.08 \\
Under19 years & 193 & 15.93 & Rural & 531 & 43.92 \\
20-35 years & 862 & 71.12 & Total & $\mathbf{1 2 0 9}$ & $\mathbf{1 0 0 . 0 0}$ \\
Over 35 years & 157 & 12.95 & & & \\
Total & $\mathbf{1 2 1 2}$ & $\mathbf{1 0 0 . 0 0}$ & & & \\
\hline Education & 128 & 10.60 & Married & 698 & 26.48 \\
Illiterate & 139 & 11.51 & Single & 513 & 73.52 \\
Primary school (grades 1-4) & 231 & 19.12 & Total & $\mathbf{1 2 0 1}$ & $\mathbf{1 0 0 . 0 0}$ \\
Middle school (grades 1-8) & 440 & 36.42 & & & \\
Secondary education & 270 & 22.35 & & & \\
Higher education & $\mathbf{1 2 0 8}$ & $\mathbf{1 0 0 . 0 0}$ & & $\mathbf{1 1 1 2}$ & $\mathbf{1 0 0 . 0 0}$ \\
Total & \multicolumn{2}{|l|}{ Total } & & \\
\hline
\end{tabular}

As can be seen in Table 1, the mean age of the women in childbirth was $26.6 \pm 6.5$ years (Mean, SD). The youngest woman in childbirth was 14 years old, and the oldest - 46 years old. About $60 \%$ were urban residents. The proportion of women in childbirth with secondary and higher education was $58.77 \%$. Over $73 \%$ were unmarried women.

Table 2. Distribution of live-born infants bymaternal and obstetric characteristics

\begin{tabular}{|l|l|l|l|l|l|}
\hline & $\begin{array}{l}\text { PNNBW } \\
(\mathrm{n}=100)\end{array}$ & $\begin{array}{l}\text { PLBWN } \\
(\mathrm{n}=120)\end{array}$ & $\begin{array}{l}\text { FTNNBW } \\
(\mathrm{n}=955)\end{array}$ & $\begin{array}{l}\text { FTNLBW } \\
(\mathrm{n}=37)\end{array}$ & $\mathrm{p}$ \\
\hline $\begin{array}{l}\text { Age } \\
\text { Mean age } \pm S D\end{array}$ & $26.4 \pm 6.7$ & $28.0 \pm 7.4$ & $26.5 \pm 6.3$ & $26.5 \pm 7.8$ & 0.02 \\
\hline $\begin{array}{l}\text { Type of birth } \\
\text { Cesarean birth(\%) }\end{array}$ & 33.00 & 58.30 & 39.00 & 48.00 & 0.001 \\
\hline $\begin{array}{l}\text { Maternal pelvic dimensions } \\
\text { Anatomically narrow pelvis(\%) }\end{array}$ & 5.00 & 8.00 & 2.57 & 7.14 & 0.001 \\
\hline $\begin{array}{l}\text { Amniotic fluid } \\
\text { Amniotic fluid deficiency and congenital } \\
\text { abnormalities(\%) }\end{array}$ & 37.11 & 44.35 & 19.45 & 22.22 & 0.001 \\
\hline
\end{tabular}




\begin{tabular}{|l|l|l|l|l|l|}
\hline $\begin{array}{l}\text { Placenta } \\
\text { Placental abnormalities (\%) }\end{array}$ & 8.89 & 20.0 & 5.58 & 25.71 & 0.001 \\
\hline $\begin{array}{l}\text { Fetal membranes } \\
\text { Abnormalities of fetal membranes(\%) }\end{array}$ & 1.05 & 2.59 & 1.31 & 2.70 & 0.641 \\
\hline $\begin{array}{l}\text { Umbilical cord } \\
\text { Umbilical cord abnormalities (\%) }\end{array}$ & 32.29 & 25.86 & 28.13 & 11.11 & 0.101 \\
\hline
\end{tabular}

We studied the prevalence of 7 RFs of the obstetric status into three age groups of women in childbirth. Significant associations were found between most RFs and preterm births and low birth weight (Table 2). Mean maternal age was significantly higher $(28.0 \pm 7.4)$ in the group of the PLBWN compared with the other three groups $(\mathrm{p}=0.02)$. The same was found for the caesarean birth, breech presentation of the fetus, maternal pelvic size abnormalities, placental abnormalities, and abnormalities of fetal membranes $(\mathrm{p}<0.05)$.

Table 3. Obstetric characteristics of women in childbirth in three age groups

\begin{tabular}{|lllll|}
\hline & Under 19 years & $20-35$ years & Over 35 years & p \\
\hline $\begin{array}{l}\text { Type of birth } \\
\text { Cesarean birth(\%) }\end{array}$ & 22.80 & 42.10 & 54.78 & 0.001 \\
\hline $\begin{array}{l}\text { Maternal pelvic dimensions } \\
\text { Anatomically narrow pelvis(\%) }\end{array}$ & 9.84 & 2.20 & - & 0.001 \\
\hline $\begin{array}{l}\text { Amniotic fluid } \\
\text { Amniotic fluid deficiency and congenital } \\
\text { abnormalities(\%) }\end{array}$ & 17.62 & 23.73 & 28.57 & 0.050 \\
\hline $\begin{array}{l}\text { Placenta } \\
\text { Placental abnormalities (\%) }\end{array}$ & 6.60 & 8.20 & 9.50 & 0.02 \\
\hline $\begin{array}{l}\text { Fetal membranes } \\
\text { Abnormalities of fetal membranes (\%) }\end{array}$ & 2.65 & 1.09 & 1.96 & 0.236 \\
\hline $\begin{array}{l}\text { Umbilical cord } \\
\text { Umbilical cord abnormalities (\%) }\end{array}$ & 24.70 & 28.90 & 23.90 & 0.001 \\
\hline $\begin{array}{l}\text { Fetal presentation } \\
\text { Breech presentation (\%) }\end{array}$ & 3.80 & 5.13 & 8.00 & 0.001 \\
\hline
\end{tabular}

The risk groups were identified: women in child birth under 19 and over 35 years of age. The proportion of caesarean births (54.78\%), amniotic fluid deficiency and congenital abnormalities (28.57\%), placental abnormalities (9.5\%) and breech presentation (8\%) were significantly higher in the older women in childbirth. An anatomically narrow pelvis was significantly more frequent $(9.84 \%)$ in young mothers (under 19 years of age) compared with the other age groups $(\mathrm{p}=0.001)$.

A quantitative assessment of risks for preterm births and low birth weight is shown in Table 4. Maternal age at delivery (under 19) was associated with 1.43 times greater risk for having a baby born before $37 \mathrm{GW}$ weighing less than $2500 \mathrm{~g}(\mathrm{OR}=1.43$; CI 1.1-2.1; $\mathrm{p}=0.01)$. Women in childbirth over 35 years of age had an increased risk for preterm births and low birth weight $(\mathrm{OR}=2.02$; $\mathrm{CI} 1.2-3.3 ; \mathrm{p}=0.001)$.

Table 4. Risk factors of obstetric status for preterm birth and low-birth weight (total and according to maternal age at pregnancy)

\begin{tabular}{|l|l|l|l|}
\hline Risk factor & OR & CI & p \\
\hline Age & & & \\
Under 19 years & 1.43 & $1.1-2.1$ & 0.01 \\
Over 35 years & 2.02 & $1.2-3.3$ & 0.001 \\
\hline Maternal pelvic size abnormalities & 3.31 & $1.50-7.31$ & 0.001 \\
Under 19years & 2.58 & $1.64-4.07$ & 0.001 \\
20-35 years & 4.93 & $3.45-7.04$ & 0.001 \\
Over 35years & - & - & - \\
\hline
\end{tabular}




\begin{tabular}{|l|l|l|l|}
\hline Breech presentation of the fetus & 7.35 & $6.14-8.79$ & 0.001 \\
Under 19 years & 20.9 & $11.9-36.8$ & 0.001 \\
20-35 years & 2.22 & $4.17-6.53$ & 0.001 \\
Over 35 years & 12.5 & $8.17-19.1$ & 0.001 \\
\hline Amniotic fluid deficiency and congenital & & & \\
abnormalities & 3.30 & $2.21-4.93$ & 0.001 \\
Under 19 years & 2.07 & $1.45-2.94$ & 0.001 \\
20-35 years & 3.44 & $2.93-4.03$ & 0.001 \\
Over 35 years & 4.16 & $3.11-5.56$ & 0.001 \\
\hline Placental abnormalities & 4.23 & $3.56-5.03$ & 0.001 \\
Under 19 years & 1.78 & $1.06-2.97$ & 0.001 \\
20-35 years & 5.41 & $4.39-6.65$ & 0.001 \\
Over 35 years & 3.27 & $2.15-4.97$ & 0.001 \\
\hline Abnormalities of fetal membranes & 2.00 & 1.34 .3 .00 & 0.001 \\
Under 19 years & 1.79 & $0.88-3.64$ & $\mathrm{NS}$ \\
20-35 years & 1.31 & $0.67-2.54$ & $\mathrm{NS}$ \\
Over 35 years & 5.09 & $2.01-12.4$ & 0.001 \\
\hline Umbilical cord abnormalities & 1.12 & $1.06-1.29$ & 0.001 \\
Under 19 years & 2.09 & $1.39-3.14$ & 0.001 \\
20-35 years & 1.16 & $1.09-1.36$ & 0.048 \\
Over 35 years & 1.69 & $1.17-4.43$ & 0.005 \\
\hline Cesarean birth & 2.28 & $1.54-3.38$ & 0.001 \\
Under 19 years & 1.82 & $1.32-2.50$ & 0.002 \\
20-35 years & 2.00 & $1.72-2.34$ & 0.001 \\
Over 35 years & 5.09 & $3.55-7.28$ & 0.001 \\
\hline
\end{tabular}

*mothers of PLBWN (cases) and mothers of FTNNBW (controls)

RFs of obstetric status increased the risk for preterm birth and low-birth weight many times in all age groups. The risk for preterm births and low birth weight was 20 times higher in young mothers where baby settle breech presentation into delivery $(\mathrm{OR}=20.9 ; \mathrm{p}=0.001)$ compared with the other age groups. In mothers older than 35 , the risk for preterm births and low birth weight was 5 times higher in cases of caesarean birth and abnormalities of fetal membranes, and 4 times higher in cases of amniotic fluid deficiency and congenital abnormalities $(p<0.05)$.

\section{DISCUSSION}

The results of our study support some previous studies about RFs of premature birth and showed some specific results. It was found that mean maternal age was significantly higher in the group of PLBWN. The risk for preterm birth and low birth weight was 1.4 times higher in mothers under 19 years of age and 2 times higher in mothers over 35 . The rate of prematurity births ranges $9-50 \%$ in the different populations $[1,2,8,11,19]$.

Over $58 \%$ of preterm births and low birth weight were caesarean births. The cesarean births were more common in women in childbirth over 35, with an odds ratio of 5.09. That could be explained with the role of acceleration on adolescent health which the main effect is functional maturity more early $[2,8,9]$. The choice of cesarean births in women under 19 and over 35 is associated with beliefs these age groups are risk groups [12].

The most common indication for cesarean births in the young age group has been cephalopelvic disproportion (CPD) and immature pelvis [7, 13]. Because of that, maternal pelvic size abnormalities are important characteristics of obstetric status included in the study. We found the proportion of maternal pelvic size abnormalities was 4 times higher in young mothers compared with 20-35-year-olds. Almost $10 \%$ of preterm birth and low-birth weight was found in mothers with pelvic size abnormalities, 5 times higher in mothers aged 20-25 and 3 times higher in mothers under 19. It has been found that the growth and development of the female pelvis are not complete at the age of 19 , and the process goes later. It has been well established that growth and development of the female pelvis are slower compared with height growth, especially in young women $[2,8,20]$. The results of maternal pelvic size abnormalities in different populations are different, as well as ethnic groups differences $[8,13,20]$. Thus, maternal pelvic size abnormalities could not be used as a reliable measure of premature births between the different populations.

Over one-fifth of the preterm births and low birth weight were associated with the breech presentation of the fetus, 3 times higher in mothers over 35 (OR=5.09) compared with mothers under $19(\mathrm{OR}=1.82)$. We assume that 
fetal presentation is more likely associated with the "behaviour" and resources of the fetus rather than maternal maturity.

One-fifth of the preterm births and low birth weight was significantly associated with the placental abnormalities, more often in the older age group (9.5\%) compared with the young age group (6.6\%). However, the risk for preterm births and low birth weight was higher in mothers aged 20-35 years $(\mathrm{OR}=5.41)$ compared with mothers over $35(\mathrm{OR}=3.27)$.

The risk for preterm births and low birth weight was 5 times greater in mothers with abnormalities of fetal membranes and older than 35. Mothers less than 19 with umbilical cord abnormalities had 2 times greater risk for preterm births and low birth weight compared with the other age groups $(\mathrm{p}<0.05)$.

\section{CONCLUSIONS}

We identified many risk factors of obstetric status for preterm birth and low birth weight. We found that the prevalence of RFs was different in the three age groups. The prevalence of RFs was higher in mothers under 19 and over 35 years of age.

The RFs of obstetric status for preterm birth and lowbirth weight vary and require to be identified during the pregnancy. That approach reduces considerably the risk of premature birth, much different health, economic and social problems for children, their families, the health system and society.

The results from the study could be used in programs for the prevention of pregnancy and prematurity.

\section{Acknowledgements}

This study has no financial support.

\section{REFERENCES:}

1. Kambourova M. [Risk factors for premature births their effect on health and social needs in early childhood] [dissertation]. Pleven (Bulgaria): Medical University of Pleven; 2014. 189 p. [in Bulgarian]

2. Vakrilova L. [Early criteria for risk assessment and prognosis in lowbirth-weight newborns] [dissertation]. Sofia (Bulgaria): Medical University of Sofia; 2011. 166 p. [in Bulgarian]

3. Kambourova M, Hristova I. [Factors family background of mothers involved in having a premature baby.] [in Bulgarian] Akush Ginekol (Sofiia). 2014;53(3):29-33. [PubMed]

4. Ivanov S. [Preterm birth and premature birth - the challenges of obstetrics and gynecology]. Health.bg. 2013 Jun;5:12-5. [in Bulgarian]

5. Boots AB, Sanchez-Ramos L, Bowers DM, Kaunitz AM, Zamora J, Schlattmann P. The short-term prediction of preterm birth: a systematic review and diagnostic metaanalysis. $\mathrm{Am}$ J Obstet Gynecol. 2014 Jan;210(1): 54.e1-54.e10. [PubMed] [Crossref]

6. Linsell L, Malouf R, Morris J, Kurinczuk JJ, Marlow N. Prognostic Factors for Poor Cognitive Development in Children Born Very Preterm or With Very Low Birth Weight: A Systematic Review. JAMA Pediatr. 2015 Dec;169(12):1162-72. [PubMed] [Crossref]

7. Mercer BM, Goldenberg RL, Das A, Moawad AH, Iams JD, Meis PJ, et al. The preterm prediction study: a clinical risk assessment system. Am J Obstet Gynecol. 1996 Jun;174(6): 1885-93. [PubMed] [Crossref]

8. Dimitrov A. [Obstetrics]. Sofia: ARSO; 2014. 301 p. [in Bulgarian]

9. Karamisheva V. [Risk assessment and behavior in preterm birth] [dissertation]. Sofia (Bulgaria: Medical University of Sofia; 2016. 182 p. [in Bulgarian].

10. Katzulov A. [Pregnancy with high risk]. Sofia: Medicine and Physical education; 1989. 247 p. [in Bulgarian]

11. Katzulov A. [Birth with high risk]. Sofia: Medicine and Physical education; 1990. 264 p. [in Bulgarian]

12. Carmichael SL, Abrams B. A critical review of the relationship between gestational weight gain and preterm delivery. Obstet Gynecol. 1997 May;89(5 Pt 2):865-73. [PubMed] [Crossref]

13. Maness SB, Buhi ER, Daley EM, Baldwin JA, Kromrey JD. Social Determinants of Health and Adolescent Pregnancy: An Analysis From the National Longitudinal Study of Adolescent to Adult Health. J Adolesc Health. 2016 Jun;58(6):636-43. [PubMed] [Crossref]

14. Farag AH, Mohammed MM, Ellaithy MI, Salama HA. Blind vaginal fetal fibronectin swab for prediction of preterm birth. J Obstet Gynaecol Res. 2015 Jul;41(7):100917. [PubMed] [Crossref]
15. Fox NS, Saltzman DH, Fishman A, Klauser CK, Gupta S, Rebarber A. Gestational age at cervical length and fetal fibronectin assessment and the incidence of spontaneous preterm birth in twins. J Ultrasound Med. 2015 Jun; 34(6):977-84. [PubMed] [Crossref]

16. Merkx A, Ausems M, Bude L, de Vries R, Nieuwenhuijze MJ. Factors affecting perceived change in physical activity in pregnancy. Midwifery. 2017 Aug;51:16-23. [PubMed] [Crossref]

17. Tucker CM, Berrien K, Menard MK, Herring AH, Daniels J, Rowley DL, et al. Predicting Preterm Birth Among Women Screened by North Carolina's Pregnancy Medical Home Program. Matern Child Health J. 2015 Nov;19(11):2438-52. [PubMed] [Crossref]

18. van der Ven $A J$, van Os $M$, van den Wijngaard L, Mochtar MH, de Bekker-Grob EW, Kazemier BM, et al. Patient's Preferences for Management Options in Relation to Preterm Birth. $J$ Health Med Informat. 2015; 6(3):189.

19. Asvanarunat E. Outcomes of gestational weight gain outside the Institute of Medicine Guidelines. J Med Assoc Thai. 2014 Nov;97(11):111925. [PubMed]

20. Abdulla SY, Al-Hadithi T. Perinatal outcome of breech presentation at the Maternity Teaching Hospital in Erbil City. JSMC. 2014; 4(2):81-85. [Crossref] 
Please cite this article as: Hristova I, Tomov S, Hinkova N, Popov Y, Simeonova J. Assessment of risk factors of obstetric status associated with premature births in women in childbirth. J of IMAB. 2020 Jan-Mar;26(1):3023-3028.

DOI: https://doi.org/10.5272/jimab.2020261.3023

Received: 10/06/2019; Published online: 30/03/2020

(c) ()

Address for correspondence:

Irena Hristova,

Department of Midwifery, Faculty of Health Care, Medical University - Pleven, 1, St. Kliment Ohridski, 5800 Pleven, Bulgaria,

E-mail: doc_hristova@abv.bg 